\title{
Comparison of seaweed pack and mudpack as treatment for knee osteoarthritis: a prospective randomized controlled study
}

\author{
Sang Hee Lee ${ }^{a}$, Ji Hoon Han ${ }^{a}$, Sung Jae Lee ${ }^{b}$, Hwi Young $\mathrm{Cho}^{c}$, Jung Heum Baek ${ }^{\mathrm{a}}$, Jae Gyoon Kim ${ }^{\mathrm{a}}$ \\ ${ }^{a}$ Department of Orthopedic Surgery, Korea University Ansan Hospital, Ansan, Republic of Korea \\ ${ }^{\mathrm{b}}$ Center for Integrative Medicine, Korean University Medical Center, Korea University College of Medicine, Seoul, Republic of Korea \\ 'Department of Physical Therapy, Gachon University, Incheon, Republic of Korea
}

Objective: For knee osteoarthritis (OA), there is a demand for alternative modalities in order to delay surgery and to avoid the side effects of medications. This study compared the effects of applying seaweed pack and mudpack for the treatment of knee OA. Design: Randomized controlled trial.

Methods: Twenty-five patients with knee OA who satisfied the criteria were included. The patients were divided into two groups according to the treatment method: mudpack $(n=12)$ and seaweed pack $(n=13)$. The two groups were treated for 20 minutes, twice a day for five continuous days at the Ocean Healing Center at Wando Island, South Korea. Participants were assessed by clinical scores (Western Ontario and McMaster Universities Osteoarthritis Index, Hospital for Special Surgery Knee Score, Knee injury and Osteoarthritis Outcome Score and 36-Item Short Form Health Survey) and lab results (erythrocyte sedimentation rate, C-reactive protein, insulin-like growth factor-1 [IGF-1], tumor necrosis factor- $\alpha$ [TNF- $\alpha$ ]) during the follow-up period.

Results: For the most part, clinical scores improved after therapy and maintained improvements for four weeks in both groups $(p<0.05)$. In the seaweed group, TNF- $\alpha$ was significantly decreased at two weeks post-therapy $(p<0.05)$. In both groups, IGF-1 was significantly increased immediately post-therapy $(p<0.05)$. There were no statistically significant differences after therapy between the groups in clinical scores and labs.

Conclusions: Seaweed packs and mudpacks had similar positive effects for knee OA. Additionally, the seaweed pack group showed decreased levels of TNF- $\alpha$ at two weeks post-treatment, which may explain the reduced inflammatory reaction. For rehabilitation therapy, use of seaweed packs may serve as an alternative modality for the treatment of knee OA.

Key Words: Climatotherapy, Knee, Mud therapy, Osteoarthritis, Seaweed therapy

\section{Introduction}

Osteoarthritis (OA) is a degenerative joint disease that mostly involves weight-bearing joints. The knee is the most commonly involved joint. Knee OA patients experience pain and functional impairment, eventually leading to impaired self-care functions and decreased quality of life [1]. As society ages, the socioeconomic burden of knee OA will inevitably increase. This makes knee OA a public health problem in addition to an individual problem [2].

Knee OA treatments include non-pharmacologic, pharmacologic, and surgical modalities targeted at relieving pain, improving joint function, and modifying risk factors for disease progression [3]. In an effort to delay arthroplasty, various treatment modalities have been offered to patients. Generally, pharmacologic modalities are used. However, pharmacological management methods are symptomatic treatment techniques as it targets the symptoms of the dis-

Received: 31 December, 2018 Revised: 10 March, 2019 Accepted: 11 March, 2019

Corresponding author: Jae Gyoon Kim (ORCID https://orcid.org/0000-0001-5086-0277)

Department of Orthopedic Surgery, Korea University Ansan Hospital, 123 Jeokgeum-ro, Danwon-gu, Ansan 15355, Republic of Korea Tel: 82-31-412-4946 Fax: 82-31-487-9502 E-mail: jgkim7437@gmail.com

(c) This is an Open-Access article distributed under the terms of the Creative Commons Attribution Non-Commercial License (http://creativecommons.org/licenses/ by-nc/4.0) which permits unrestricted non-commercial use, distribution, and reproduction in any medium, provided the original work is properly cited.

Copyright (๑) 2019 Korean Academy of Physical Therapy Rehabilitation Science 
ease rather than its cause [4]. In addition, long-term use of medications is risky to some patients due to side effects, such as gastrointestinal distress and cardiovascular problems $[5,6]$. Thus, alternative modalities that have few side effects and significant efficacy to alleviate the OA severity and preserve the structural integrity of joint tissues are needed [7].

Thalassotherapy is an alternative modality that uses seawater, mud, sand, seaweed, and the sea environment for treatment. Several studies have suggested that thalassotherapy has a beneficial effect on knee OA patients [8-11]. In particular, studies have focused on mud therapy. Several studies have analyzed the effectiveness of mud pack used for knee OA and compared it to other intervention procedures. Results have shown improvements in pain, functional capacity, and quality of life [12-17]. In a prospective controlled study of 147 knee OA patients, mudpack therapy produced immediate effects on perceived pain and quality of life and reduced the consumption of specific drugs [12]. Bellometti et al. [15] reported that mud packs affect several biochemical markers and has anti-rheumatic actions. It has a protective effect on cartilage homeostasis. Evcik et al. [16] reported positive effects of balneotherapy and mudpack therapy even three months after therapy.

Studies on seaweed packs are relatively rare. Some studies have shown a positive effect of applying seaweed extract on knee OA when taken orally [18-22]. Frestedt et al. [20] researched the impact of a natural seaweed-derived mineral supplement (Aquamin F) for knee OA. Subjects $(n=29)$ were randomized to receive either Aquamin $(2,400 \mathrm{mg} / \mathrm{d})$ or a placebo for up to twelve weeks. Results showed that Aquamin may increase range of motion and walking distances [20]. Sayed et al. [7] studied the effects of red algae in dry powder form and gel form on some relevant factors of OA progression and assessed its safety in vitro. Their study found that red algae can be considered to be an inflammatory-proteinase-oxidant inhibitor [7]. However, there have been no studies on the effects of applying seaweed pack as treatment for knee OA patients. The purpose of our study was to investigate whether seaweed packs had similar positive effects in patients with knee OA as those of mudpack therapy. We hypothesized that using seaweed packs would have an equal or superior effect to using mudpack.

\section{Methods}

\section{Design}

This was a prospective randomized study comparing the effects of seaweed packs and mudpacks for knee OA. Previous studies have not evaluated the effect of using seaweed packs for knee OA and so this study was designed as a pilot study preceding subsequent large-scale studies. We referred to methods used by other studies with a similar endpoint to estimate the number of subjects that might be needed for this pilot study [20].

\section{Participants}

Patients with the following conditions were enrolled in the study between April 2018 and August 2018: male and female outpatients with both or unilateral knee OA; aged 50-80 years; symptoms present for at least three months; Kellgren-Lawrence radiological grade (K-L grade) of 2 or 3. The exclusion criteria were inflammatory joint disorders (rheumatic arthritis), ischemic heart disease, uncontrolled diabetes mellitus, central nervous system lesions (epilepsy, brain infarction, severe headache, history of loss of consciousness), total knee replacement arthroplasty in at least one joint, poor cognitive function, and poor mobility.

Recruitment was carried out by advertisements in outpatient clinics in Korea University Ansan Hospital after approval by the Institutional Review Board. A flow chart depicting the patient analysis procedure is presented in Figure 1. Twenty-five patients were recruited for the study. Subjects were divided into two groups. All patients completed the study. This study was conducted between April 2018 and December 2018. Therapy was performed on September 3-7, 2018 at the Ocean Healing Center on Wando Island, South Korea. All study participants spontaneously agreed to participate in the study, received written information, and signed the informed consent form before the study. The study was approved by the Institutional Review Board of Korea University Ansan Hospital (IRB no. 2018AS0086).

\section{Intervention}

The participants were classified into two groups using the permuted block randomization method. Group $1(n=13)$ received mudpack therapy, and group $2(n=12)$ received seaweed pack therapy at the Ocean Healing Center at Wando Island. The therapy protocol was decided by referring previous studies [12-14,16]. Before starting therapy, the af- 


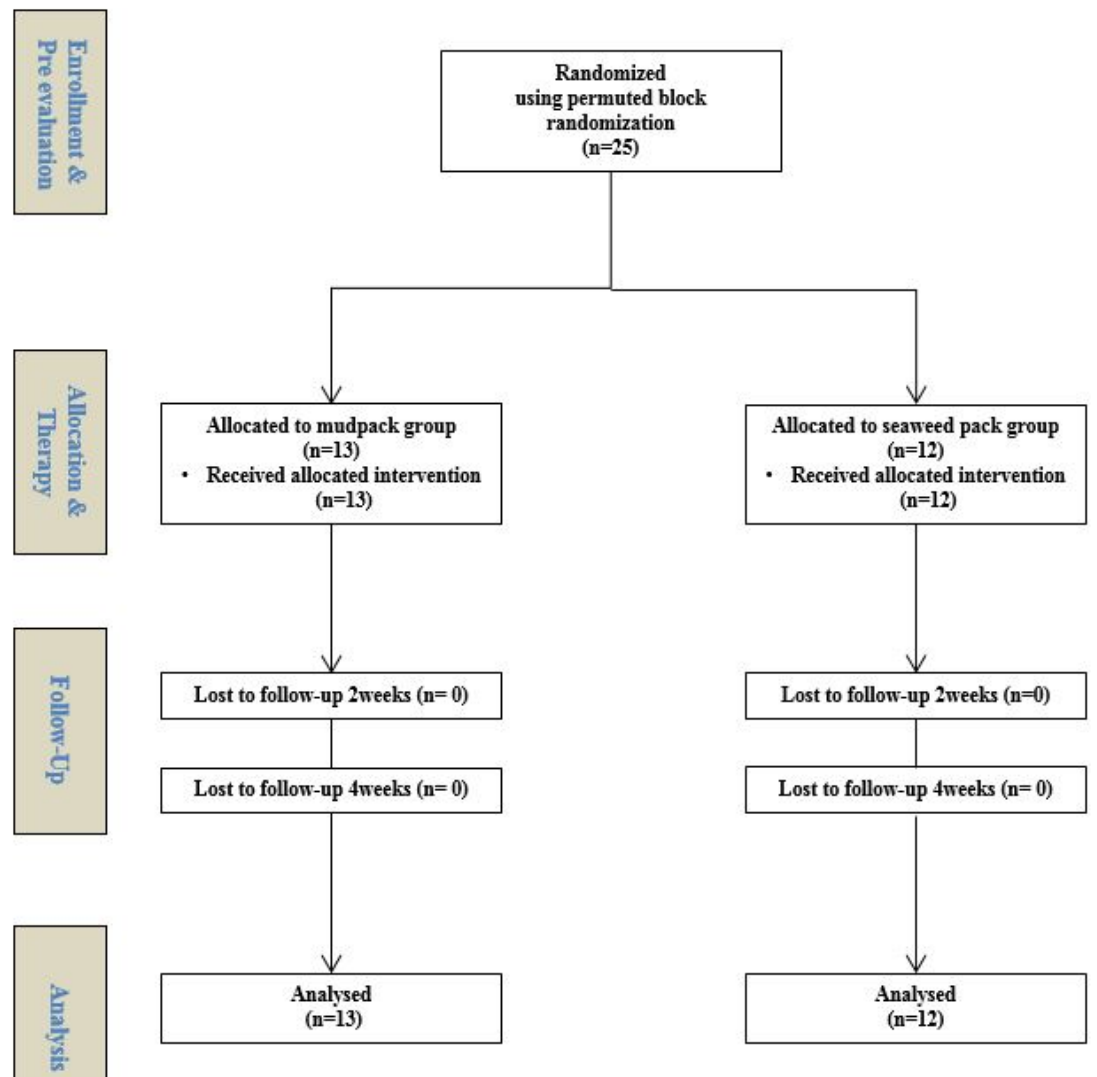

Figure 1. Flow chart depicting the patient analysis procedure.

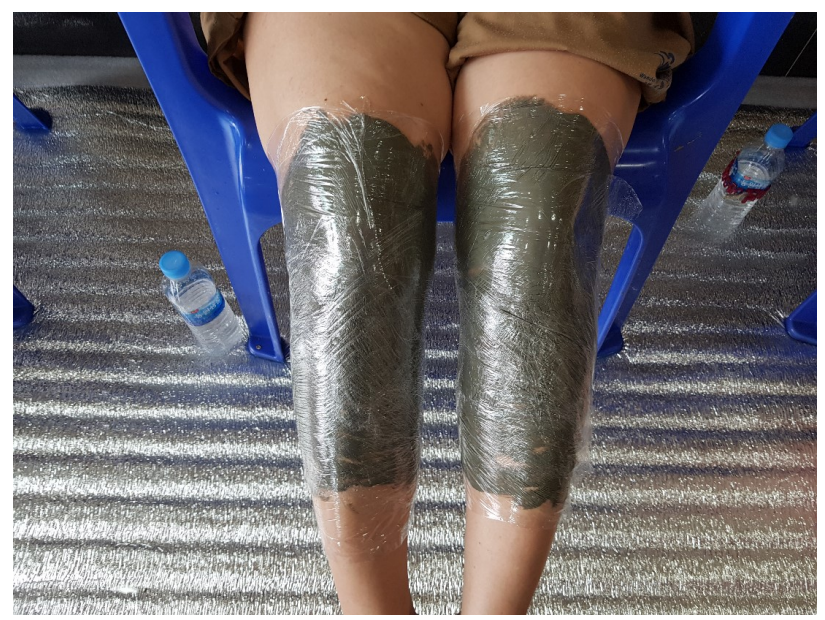

Figure 2. Mudpack application.

fected knee was washed for five minutes with $38^{\circ} \mathrm{C}$ seawater in both groups. The mud pack was made by heating mud from Wando Island with water at $39^{\circ} \mathrm{C}-40^{\circ} \mathrm{C}$ for gelation. It was applied around the knee from mid-thigh to mid-calf and wrapped using plastic wrap (Figure 2). The seaweed pack was made from ground sea mustard and kelp gathered from

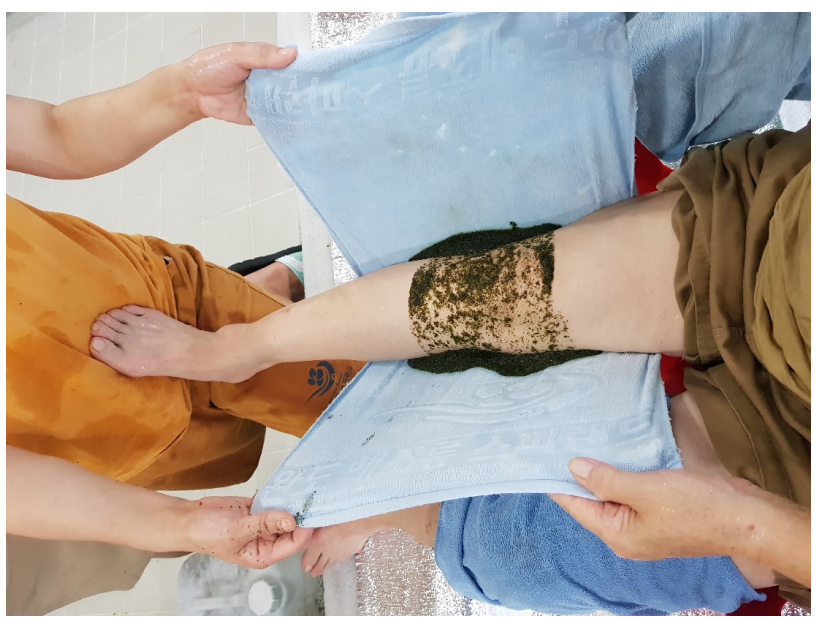

Figure 3. Seaweed pack application.

Wando Island mixed with water at $39^{\circ} \mathrm{C}-40^{\circ} \mathrm{C}$ for gelation. With a towel supporting the knee, the seaweed pack was poured onto the affected knee and covered with the towel (Figure 3). Both groups received pack therapy for $20 \mathrm{mi}-$ nutes on the affected knee twice a day for five days. After pack therapy, the knee was washed using seawater. Pack 
therapy was performed at 11:00 AM and 2:00 PM. Both groups rested during the rest period. Programs about taking a walk along the beach and practicing yoga were administered only to those who wanted to participate.

Heavy metals and mineral ingredients in the mud and seaweed were analyzed by the Center of Natural Resources Research, Jeonnam Bioindustry Foundation for Evaluating Human Safety. Lead $(\mathrm{Pb})$, arsenic $(\mathrm{As})$, cadmium $(\mathrm{Cd})$, and mercury $(\mathrm{Hg})$ concentrations were measured. The results showed trace amounts of heavy metals, which was below the safety standards of the Korea Food \& Drug Administration, demonstrating the safety of mud and seaweed for use in packs. The mineral ingredients of the mud were composed of $0.80 \mathrm{ppm}$ potassium $(\mathrm{K}), 0.75 \mathrm{ppm}$ sodium $(\mathrm{Na}), 0.53$ ppm calcium $(\mathrm{Ca})$, and $0.80 \mathrm{ppm}$ magnesium $(\mathrm{Mg})$. The mineral ingredients of the sea mustard were composed of $6.53 \mathrm{ppm} \mathrm{K}, 2.75 \mathrm{ppm} \mathrm{Na}, 1.00 \mathrm{ppm} \mathrm{Ca}$, and $0.56 \mathrm{ppm} \mathrm{Mg}$. The mineral ingredients of the kelp were composed of 6.00 ppm K, 2.07 ppm Na, 0.70 ppm Ca, and $0.52 \mathrm{ppm} \mathrm{Mg}$.

\section{Outcome}

Various scoring systems were used to evaluate the effects of the treatments for knee OA. Knee function, pain, and quality of life were measured using the Western Ontario and McMaster Universities Osteoarthritis Index (WOMAC), Hospital for Special Surgery Knee Score (HSS), Knee injury and Osteoarthritis Outcome Score (KOOS), and 36-Item Short Form Health Survey (SF-36). Each questionnaire was administered four times (pre-therapy, immediately post-therapy, two weeks post-therapy, four weeks post- therapy). Patients completed self-assessment forms without assistance. Clinical scores from each follow-up period were compared to pre-therapy clinical scores within each group. The clinical score at each follow-up period and the difference values between pre-therapy and each follow-up period were also analyzed between groups.

In addition, to investigate the objective effect on knee OA, serum levels of erythrocyte sedimentation rate (ESR), C-reactive protein (CRP), insulin-like growth factor-1 (IGF-1), and tumor necrosis factor- $\alpha$ (TNF- $\alpha$ ) were measured. Blood samples were collected at pre-therapy, immediate post-therapy, and two weeks post-therapy.

\section{Statistical analysis}

Statistical analysis was performed using IBM SPSS Statistics ver. 20.0 software (IBM Co., Armonk, NY, USA). Due to the small sample size, non-parametric methods were used in statistical calculations after evaluation of normality. All relevant clinical and demographic variables were tested between groups. Data obtained from the knee score questionnaires and blood samples were analyzed. The MannWhitney test was used to compare results between groups. The Friedman test was used to compare results between different periods within a given group. The significance value was 0.05 .

\section{Results}

There were no statistically significant difference in demographic data between the two groups in terms of age, gender, disease severity, or affected side (Table 1). The mean age was 65.5 and 60.5 years, and the mean disease severity in terms of K-L grade was 2.41 and 2.38, for the mudpack group and seaweed pack group, respectively.

\section{Clinical scores}

Figure 4 shows changes in WOMAC, HSS, KOOS (pain, symptoms, activities of daily living, sports, quality of life), and SF-36 (emotional well-being, pain, general health) in both groups. In the mudpack group, the clinical scores for immediate post-therapy and two and four weeks post-therapy were compared to the pre-therapy scores. Most of the scores improved immediately post-therapy, and at two and four weeks post-therapy. Specifically, at four weeks posttherapy, the positive effect was maintained in all scores $(p<0.05)$ except the pain section of SF-36 $(p=0.07)$.

In seaweed pack group, most of the scores improved immediately post-therapy, and at two and four weeks after therapy (Figure 4). Four weeks after therapy, the positive effect was maintained in all scores $(p<0.05)$ except for the WOMAC $(p=0.05)$.

In addition, clinical scores after therapy were compared between groups for each time period (Table 2). There were

Table 1. Demographics and degree of satisfaction with therapy by patient group

$(\mathrm{N}=25)$

\begin{tabular}{lccc}
\hline \multicolumn{1}{c}{ Variable } & Mudpack & Seaweed pack & $p$-value \\
\hline Age (y) & $65.5(6.0)$ & $60.5(19.7)$ & 0.982 \\
Sex (female:male) & $12: 0$ & $13: 0$ & 1.000 \\
Disease severity & $2.4(0.5)$ & $2.4(0.5)$ & 0.891 \\
Right:left:bilateral & $5: 3: 4$ & $6: 2: 5$ & 0.663 \\
\hline
\end{tabular}

Values are presented as mean (SD) or number only.

Disease severity was evaluated using Kellgren-Lawrence radiological grade. 

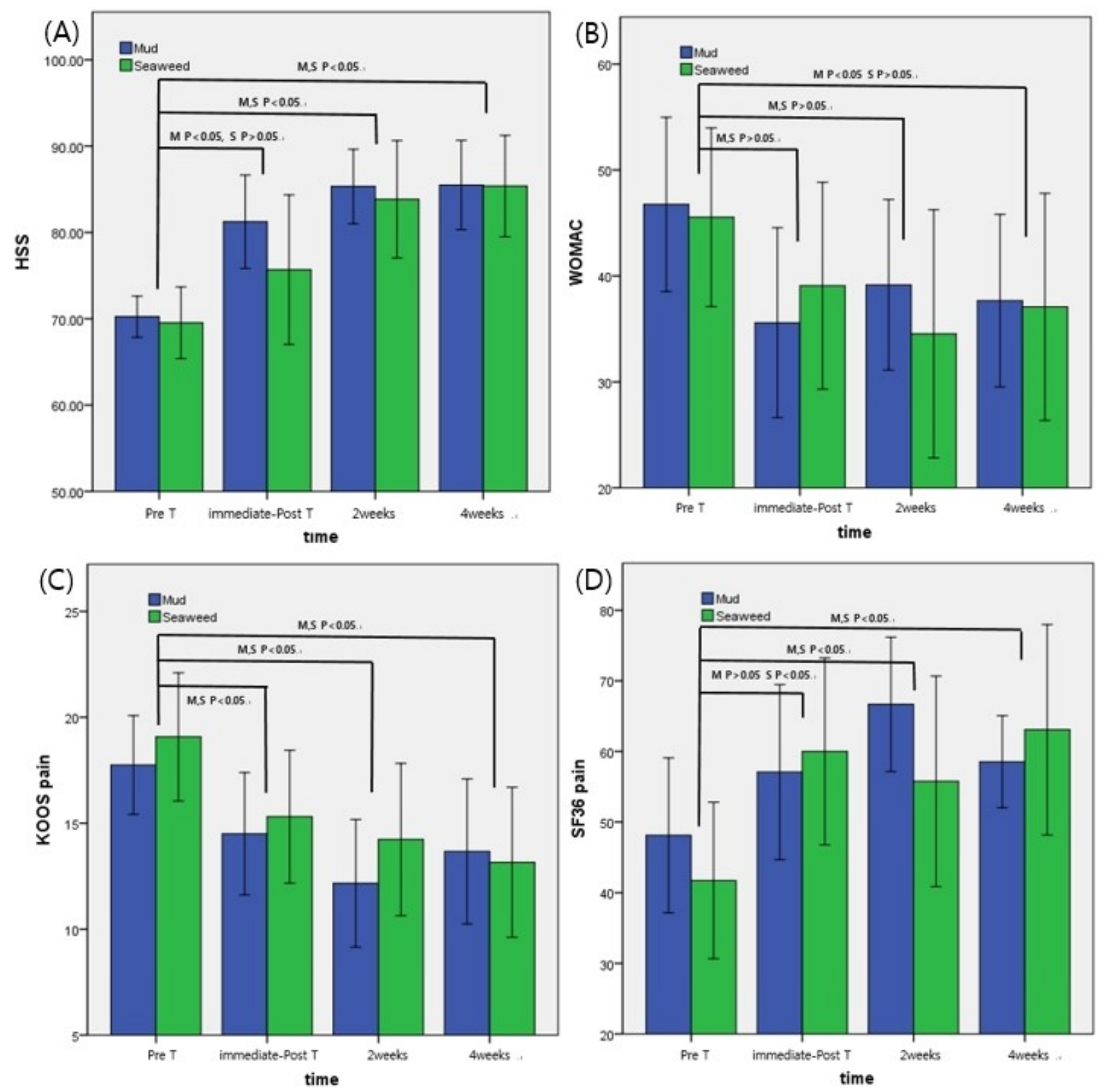

Figure 4. Change in clinical scores. (A) Hospital for Special Surgery Knee Score (HSS). (B) The Western Ontario and McMaster Universities Osteoarthritis Index (WOMAC). (C) The Knee injury and Osteoarthritis Outcome Score (KOOS)-pain. (D) The 36-Item short Form Health Survey (SF-36) Questionnaire-pain. M: mudpack group, S: seaweed pack group, T: therapy.

no statistically significant differences between the two groups $(p>0.05)$. The differences between values pre- and posttherapy (post-therapy value minus pre-therapy value) were compared between groups for each post-therapy period (Table 3). There were no statistically significant differences between the two groups $(p>0.05)$.

\section{Laboratory findings}

Table 4 shows the lab results and the differences between their values pre- and post-therapy in each group. Serum IGF-1 values were significantly increased immediately post-therapy in both groups ( $p=0.002$ in mudpack group, $p=0.03$ in seaweed group). Serum IGF- 1 and serum TNF- $\alpha$ were significantly decreased at two weeks post-therapy in the seaweed pack group $(p=0.02, p=0.005)$ (Figure 5). The rest of the labs, including ESR and CRP, did not show significant differences in any follow-up periods in either group. Lab results of each follow-up period and the differences be- 
Table 2. Comparison of clinical scores between groups during each period

$(\mathrm{N}=25)$

\begin{tabular}{|c|c|c|c|c|c|c|c|c|}
\hline \multirow[b]{2}{*}{ Group } & \multicolumn{2}{|c|}{ Pre-therapy } & \multicolumn{2}{|c|}{ Immediate post-therapy } & \multicolumn{2}{|c|}{2 weeks } & \multicolumn{2}{|c|}{4 weeks } \\
\hline & Mean (SD) & $\begin{array}{c}p \text {-value } \\
\text { (group } \\
\text { difference) }\end{array}$ & Mean (SD) & $\begin{array}{c}p \text {-value } \\
\text { (group } \\
\text { difference) }\end{array}$ & Mean (SD) & $\begin{array}{c}p \text {-value } \\
\text { (group } \\
\text { difference) }\end{array}$ & Mean (SD) & $\begin{array}{c}p \text {-value } \\
\text { (group } \\
\text { difference) }\end{array}$ \\
\hline \multicolumn{9}{|l|}{ WOMAC } \\
\hline Mud (n=12) & 43.4 (11.4) & 0.981 & $34.0(14.0)$ & 0.732 & 38.4 (13.6) & 0.212 & $33.9(11.2)$ & 0.611 \\
\hline Seaweed $(n=13)$ & $46.3(13.5)$ & & $43.6(17.4)$ & & $42.3(20.1)$ & & $41.8(18.0)$ & \\
\hline \multicolumn{9}{|l|}{ HSS } \\
\hline Mud (n=12) & $70.0(4.0)$ & 0.733 & $82.7(8.9)$ & 0.440 & $85.2(6.6)$ & 0.853 & $87.9(4.6)$ & 0.982 \\
\hline Seaweed $(n=13)$ & $67.6(6.4)$ & & $74.1(15.4)$ & & $80.1(13.0)$ & & $83.0(11.7)$ & \\
\hline \multicolumn{9}{|l|}{ KOOS } \\
\hline \multicolumn{9}{|l|}{ Pain } \\
\hline Mud (n=12) & $17.9(3.4)$ & 0.573 & $14.2(4.5)$ & 0.814 & $11.0(4.7)$ & 0.502 & $12.7(5.0)$ & 0.693 \\
\hline Seaweed $(n=13)$ & $18.6(4.9)$ & & $16.5(5.7)$ & & $16.3(6.6)$ & & $14.1(6.7)$ & \\
\hline \multicolumn{9}{|l|}{ Symptoms } \\
\hline $\operatorname{Mud}(\mathrm{n}=12)$ & $11.4(2.9)$ & 0.375 & $9.9(2.9)$ & 0.982 & $7.7(4.4)$ & 0.692 & $8.0(3.3)$ & 0.696 \\
\hline Seaweed $(n=13)$ & $15.1(3.6)$ & & $12.1(5.2)$ & & $11.4(6.1)$ & & $11.3(5.9)$ & \\
\hline \multicolumn{9}{|l|}{$\mathrm{ADL}$} \\
\hline $\operatorname{Mud}(\mathrm{n}=12)$ & $28.9(5.0)$ & 0.272 & $21.9(8.6)$ & 0.733 & $20.7(8.1)$ & 0.949 & $21.0(8.2)$ & 0.810 \\
\hline Seaweed $(n=13)$ & $33.5(10.3)$ & & $23.0(15.1)$ & & $28.1(17.0)$ & & $25.3(14.6)$ & \\
\hline \multicolumn{9}{|l|}{ Sports } \\
\hline Mud $(n=12)$ & $15.8(1.5)$ & 0.813 & $11.8(4.6)$ & 1.000 & $12.2(4.8)$ & 0.503 & $11.8(3.7)$ & 0.980 \\
\hline Seaweed $(n=13)$ & $16.5(2.2)$ & & $12.5(5.5)$ & & $13.1(6.3)$ & & $13.5(6.0)$ & \\
\hline \multicolumn{9}{|l|}{ QOL } \\
\hline Mud (n=12) & $9.7(2.5)$ & 0.084 & $8.0(3.5)$ & 0.851 & $9.3(1.2)$ & 0.107 & $8.1(2.7)$ & 0.653 \\
\hline Seaweed $(n=13)$ & $12.1(1.9)$ & & $8.6(4.2)$ & & $9.3(4.0)$ & & $8.0(4.4)$ & \\
\hline \multicolumn{9}{|l|}{ SF-36 } \\
\hline \multicolumn{9}{|l|}{ Emotion wellbeing } \\
\hline $\operatorname{Mud}(\mathrm{n}=12)$ & $50.0(8.7)$ & 0.258 & $69.3(17.0)$ & 0.850 & $53.8(14.7)$ & 0.106 & $67.6(17.9)$ & 0.418 \\
\hline Seaweed $(n=13)$ & $55.5(19.5)$ & & $58.0(15.3)$ & & $64.4(11.1)$ & & $66.0(9.8)$ & \\
\hline \multicolumn{9}{|l|}{ Pain } \\
\hline $\operatorname{Mud}(\mathrm{n}=12)$ & $47.8(18.4)$ & 0.549 & $55.8(21.7)$ & 0.577 & $67.8(17.0)$ & 0.475 & $60.6(9.2)$ & 0.173 \\
\hline Seaweed $(n=13)$ & $39.7(16.6)$ & & $59.9(24.9)$ & & $44.7(25.7)$ & & $53.4(26.4)$ & \\
\hline
\end{tabular}

WOMAC: Western Ontario and McMaster Universities Osteoarthritis Index, HSS: Hospital for Special Surgery Knee Score, KOOS: Knee injury and Osteoarthritis Outcome Score, SF-36: 36-Item Short Form Health Survey, ADL: activities of daily living, QOL: quality of life.

tween pre- and post-therapy values (post-therapy value minus pre-therapy value) were compared between groups for each follow-up period. There were no significant differences between groups $(p>0.05)$.

\section{Discussion}

The above results show that seaweed pack and mud pack have similar positive effects on knee OA. Improvement of pain, function, and quality of life were observed throughout the four-week follow-up period after both treatments. The seaweed pack group showed decreasing TNF- $\alpha$ levels at two weeks post-therapy, which indicated a reduction of the inflammatory reaction. To the best of our knowledge, this is the first study of the effects of using seaweed pack for knee OA.

There was no statistically significant difference in the post-therapy clinical scores and laboratory findings between the mudpack group and the seaweed pack group. Mud pack has been proven to be effective on knee OA through many studies [13-15,23-25]. However, as stated above, there have been no studies on the use of seaweed packs. The results of this study showed seaweed packs to be as effective as mudpacks used on knee OA patients. Therefore, in rehabilitation therapy, seaweed packs may serve as a good alternative modality for knee OA. 
Table 3. Difference values in clinical scores pre- and post-therapy for each treatment group

$(\mathrm{N}=25)$

\begin{tabular}{|c|c|c|c|c|c|c|}
\hline \multirow[b]{2}{*}{ Group } & \multicolumn{2}{|c|}{ Immediate post-therapy-pre-therapy } & \multicolumn{2}{|c|}{2 weeks-pre-therapy } & \multicolumn{2}{|c|}{4 weeks-pre-therapy } \\
\hline & Mean (SD) & $\begin{array}{l}p \text {-value (group } \\
\text { difference) }\end{array}$ & Mean (SD) & $\begin{array}{c}p \text {-value (group } \\
\text { difference) }\end{array}$ & Mean (SD) & $\begin{array}{l}p \text {-value (group } \\
\text { difference) }\end{array}$ \\
\hline \multicolumn{7}{|l|}{$\triangle \mathrm{WOMAC}$} \\
\hline Mud (n=12) & $-1.2(19.6)$ & 0.412 & $-7.6(21.2)$ & 0.652 & $-9.1(16.0)$ & 0.772 \\
\hline Seaweed $(n=13)$ & $-6.5(16.0)$ & & $-11.0(20.1)$ & & $-8.5(18.0)$ & \\
\hline \multicolumn{7}{|l|}{$\Delta \mathrm{HSS}$} \\
\hline Mud (n=12) & $11.0(6.9)$ & 0.272 & $15.1(8.6)$ & 0.891 & $15.3(7.8)$ & 0.852 \\
\hline Seaweed $(n=13)$ & $6.2(10.8)$ & & $14.3(8.4)$ & & $15.9(7.3)$ & \\
\hline \multicolumn{7}{|l|}{$\Delta \mathrm{KOOS}$} \\
\hline \multicolumn{7}{|l|}{ Pain } \\
\hline Mud (n=12) & $-3.3(4.8)$ & 0.771 & $-5.6(5.9)$ & 0.892 & $-4.1(5.7)$ & 0.211 \\
\hline Seaweed $(n=13)$ & $-3.8(5.3)$ & & $-4.9(6.1)$ & & $-5.9(5.2)$ & \\
\hline \multicolumn{7}{|l|}{ Symptoms } \\
\hline Mud (n=12) & $-0.8(2.6)$ & 0.111 & $-3.1(4.4)$ & 0.735 & $-2.8(3.7)$ & 0.442 \\
\hline Seaweed $(n=13)$ & $-3.3(3.8)$ & & $-3.9(3.2)$ & & $-4.1(3.5)$ & \\
\hline \multicolumn{7}{|l|}{$\mathrm{ADL}$} \\
\hline Mud (n=12) & $-6.3(8.3)$ & 0.252 & $-7.8(7.8)$ & 0.773 & $-7.2(7.0)$ & 0.447 \\
\hline Seaweed $(n=13)$ & $-11.0(10.9)$ & & $-9.1(10.1)$ & & $-9.8(8.1)$ & \\
\hline \multicolumn{7}{|l|}{ Sports } \\
\hline Mud (n=12) & $-3.9(3.8)$ & 0.771 & $-3.0(4.1)$ & 0.812 & $-3.7(3.0)$ & 0.576 \\
\hline Seaweed $(n=13)$ & $-3.7(3.8)$ & & $-3.8(4.9)$ & & $-3.3(4.3)$ & \\
\hline \multicolumn{7}{|l|}{ QOL } \\
\hline $\operatorname{Mud}(\mathrm{n}=12)$ & $-1.8(4.5)$ & 0.381 & $-0.8(2.6)$ & 0.032 & $-2.3(3.4)$ & 0.147 \\
\hline Seaweed $(n=13)$ & $-3.7(3.0)$ & & $-3.9(3.2)$ & & $-4.5(3.7)$ & \\
\hline \multicolumn{7}{|l|}{$\Delta \mathrm{SF}-36$} \\
\hline \multicolumn{7}{|l|}{ Emotion wellbeing } \\
\hline $\operatorname{Mud}(\mathrm{n}=12)$ & $18.4(17.1)$ & 0.117 & $7.0(15.6)$ & 0.814 & $17.0(20.3)$ & 0.656 \\
\hline Seaweed $(n=13)$ & $7.0(15.6)$ & & $10.1(12.6)$ & & $12.6(15.2)$ & \\
\hline \multicolumn{7}{|l|}{ Pain } \\
\hline $\operatorname{Mud}(\mathrm{n}=12)$ & $9.0(28.8)$ & 0.302 & $18.5(19.7)$ & 0.503 & $10.4(18.1)$ & 0.193 \\
\hline Seaweed $(n=13)$ & $18.3(14.5)$ & & $14.0(22.2)$ & & $21.4(21.1)$ & \\
\hline \multicolumn{7}{|l|}{ General health } \\
\hline $\operatorname{Mud}(\mathrm{n}=12)$ & $1.3(8.0)$ & 0.053 & $7.1(17.4)$ & 0.440 & $9.2(12.0)$ & 0.982 \\
\hline Seaweed $(n=13)$ & $10.8(10.6)$ & & $2.2(10.3)$ & & $9.2(9.1)$ & \\
\hline
\end{tabular}

$\Delta$ : difference value, WOMAC: Western Ontario and McMaster Universities Osteoarthritis Index, HSS: Hospital for Special Surgery Knee Score, KOOS: Knee injury and Osteoarthritis Outcome Score, SF-36: 36-Item Short Form Health Survey, ADL: activities of daily living, QOL: quality of life.

These results are attributed to several mechanisms of the therapy. As is well known, the heat effect of a mud pack increases the pain threshold by affecting sensory and muscle endings and decreasing inflammation [16,26,27]. Melzack et al. [28] described the gate control theory of pain acting via heat receptors and mechanoreceptors. In reaction to heat, serum $\beta$-endorphin, cortisol, and catecholamine levels increase. $\beta$-endorphin is released and washes out the pain mediators by peripheral vasodilation and induces euphoria, suggesting the role of endogenous opioids. Cortisol and catecholamine have an anti-inflammatory effect. In response to heat, the elasticity of collagen-rich tissues increases, muscle spasms decrease, which appears to reduce pain and improve joint function [23].

Separate from the heating effect, the mudpack itself affects several biochemical markers and has anti-rheumatic effects. It has a positive effect on the markers of antioxidant status (increasing myeloperoxidase and nitric oxide) and on cartilage degradation (decreasing matrix metalloproteinase-3 and adiponectin, increasing IFG-1) [13]. It also decreases the level of inflammatory mediators (interleukin-1-beta, TNF- $\alpha$, prostaglandin E2, and leukotriene B4) [6,29]. 
Table 4. Lab results before and after treatment in both groups

$(\mathrm{N}=25)$

\begin{tabular}{|c|c|c|c|c|c|}
\hline \multirow{2}{*}{ Group } & \multirow{2}{*}{$\begin{array}{l}\text { Pre-therapy } \\
\text { Mean (SD) }\end{array}$} & \multicolumn{2}{|c|}{ Immediate post-therapy } & \multicolumn{2}{|c|}{2 weeks } \\
\hline & & Mean (SD) & $p$-value & Mean (SD) & $p$-value \\
\hline \multicolumn{6}{|l|}{ Serum } \\
\hline \multicolumn{6}{|l|}{$\operatorname{ESR}(\mathrm{mm} / \mathrm{h})$} \\
\hline $\operatorname{Mud}(\mathrm{n}=12)$ & $20.2(14.5)$ & $18.0(14.4)$ & 0.142 & $17.3(14.8)$ & 0.114 \\
\hline Seaweed $(n=13)$ & $12.3(9.7)$ & $11.3(10.2)$ & 0.082 & $12.3(10.5)$ & 0.146 \\
\hline \multicolumn{6}{|l|}{$\mathrm{CRP}(\mathrm{mg} / \mathrm{dL})$} \\
\hline $\operatorname{Mud}(\mathrm{n}=12)$ & $0.2(0.3)$ & $0.2(0.3)$ & 0.133 & $0.2(0.2)$ & 0.684 \\
\hline Seaweed $(n=13)$ & $0.2(0.3)$ & $0.3(0.5)$ & 0.932 & $0.1(0.1)$ & 0.183 \\
\hline \multicolumn{6}{|l|}{ IGF-1 (ng/mL) } \\
\hline Mud (n=12) & $106.9(48.5)$ & $144.2(54.9)$ & $<0.001$ & $96.4(33.2)$ & 0.214 \\
\hline Seaweed $(n=13)$ & $98.5(33.7)$ & $114.1(31.8)$ & 0.032 & $72.5(20.3)$ & 0.035 \\
\hline \multicolumn{6}{|l|}{$\mathrm{TNF}-\alpha(\mathrm{pg} / \mathrm{mL})$} \\
\hline Mud (n=12) & $8.2(3.3)$ & $9.8(9.0)$ & 0.332 & $7.8(4.2)$ & 0.124 \\
\hline Seaweed $(n=13)$ & $7.2(0.9)$ & $7.3(0.5)$ & 0.653 & $6.8(0.7)$ & 0.010 \\
\hline
\end{tabular}

ESR: erythrocyte sedimentation rate, CRP: c-reactive protein, IGF-1: insulin-like growth factor-1, TNF- $\alpha$ : tumor necrosis factor- $\alpha$.

(A)

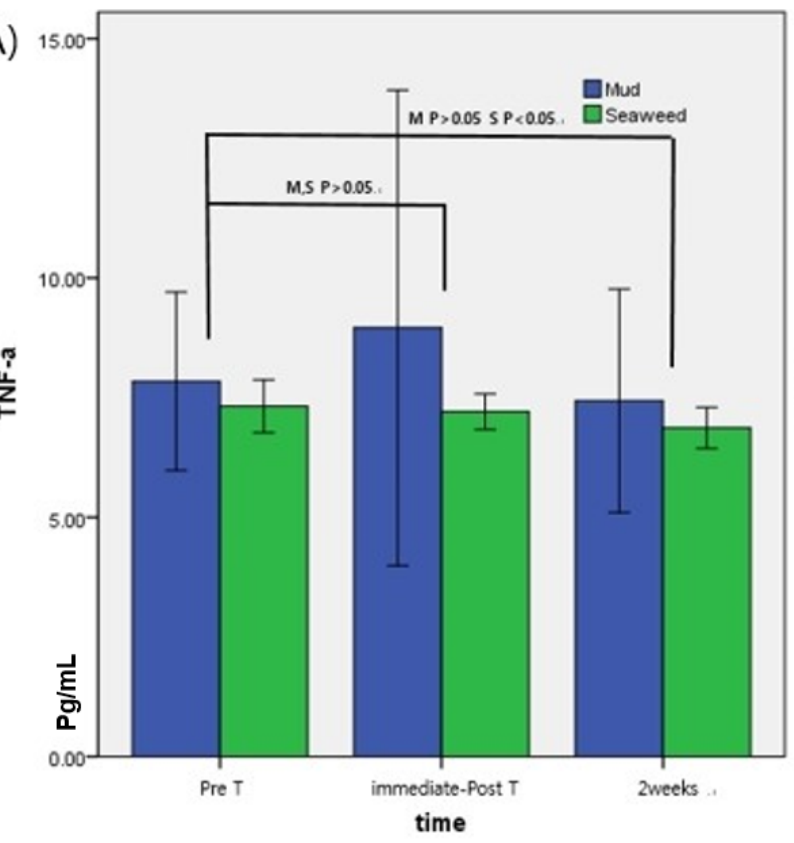

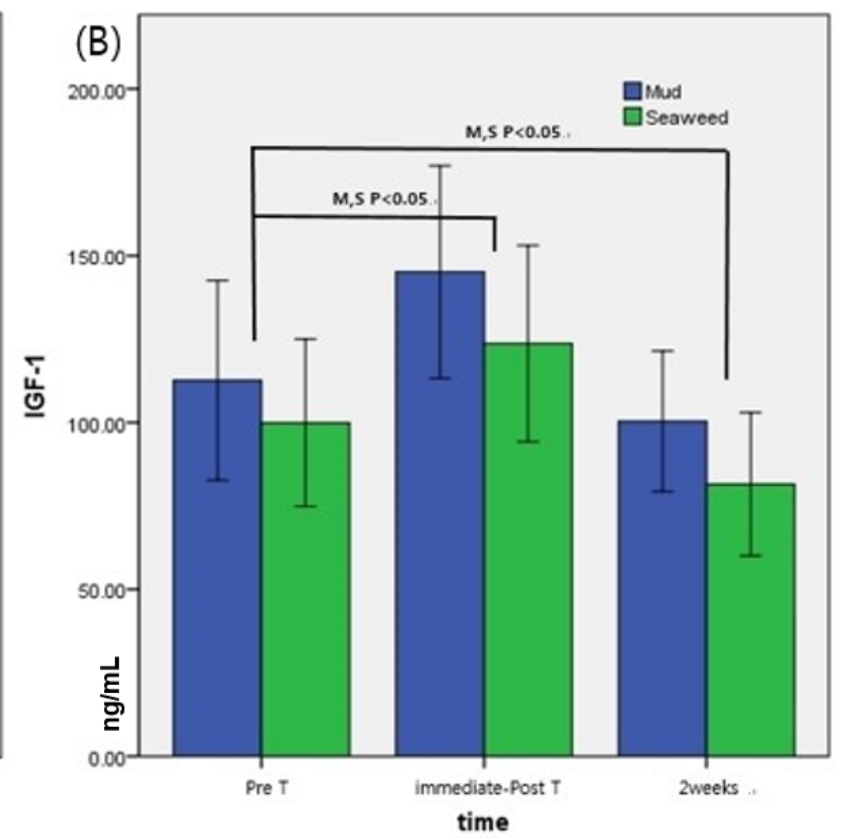

Figure 5. Change in labs. (A) Tumor necrosis factor- $\alpha$ (TNF- $\alpha$ ). (B) Insulin growth fator-1 (IGF-1). M: mudpack group, S: seaweed pack group, T: therapy.

Some studies have reported that substances in mud extract can permeate the skin and have definite effects on spontaneous contractile activity of smooth muscle tissue [30,31]. These results imply that the chemical properties of the mud contribute to the beneficial effects of mud pack therapy. However, which elements are important and the optimal concentrations for treatment remain unclear [30].

In addition, seaweed extract contain at least two major components for anti-inflammatory activity: fucoidans and polyphloroglucinols (algal polyphenols) [19]. Fucoidan is a potent selectin blocker and has been used experimentally to prevent inflammatory damage after ischemic events. Polyphloroglucinols also have profound antioxidant activity, which can also contribute to anti-inflammatory effects $[18,19]$. Some studies have reported the effects of taking natural seaweed-derived mineral supplements for knee OA. 
Frestedt et al. [20] researched the impact of a seaweed-derived mineral supplements (Aquamin F). Results showed that Aquamin may increase range of motion and walking distances [20]. Shin et al. [22] showed that phlorotannin-rich extracts of Ecklonia cava, a species of brown alga, had strong therapeutic potential as treatment for arthritis. Most studies have used seaweed extract taken orally, so we could not be certain that the same effect would be present when using seaweed in pack therapy. However, substances permeating the skin from a seaweed pack might be expected to have a similar positive effect to that observed with mudpack therapy. There has been a lack of scientific evidence supporting the use of seaweed in the form of a pack. This study showed that the positive effects of using seaweed packs are equal to that of using mudpack therapy for knee OA. Further studies about the mechanism of the therapeutic effect are needed.

The results of this study showed that the serum IFG-1 increased immediately post-therapy and decreased at two weeks after therapy in both groups, although there was a significant immediate post-therapy effect in the mud pack group. In addition, the serum TNF- $\alpha$ did not change immediately post-therapy in either group, and decreased at two weeks post-therapy in both groups, although there was a significant difference at two weeks post-therapy in the seaweed group. IGF-1 is an important growth-promoting peptide. It has anabolic and protective properties and plays a role in cartilage repair [32]. Despite these roles, Kim et al. [33] reported that serum and synovial IGF-I levels were not related with pain intensity and severity of knee OA. In a systematic review, it was concluded that there is moderate evidence for no association between serum IGF-1 and radiographic OA [32]. Thus, there is controversy over the use of IGF-1 as an index of OA prognosis. TNF- $\alpha$ is the key player among pro-inflammatory cytokines involved in OA [34]. It is a protein produced predominately by activated macrophages, which affects the production of cytokines including interleukin-6 and interleukin-8 [35]. TNF- $\alpha$ has shown characteristics as a marker of treatment efficacy, and mixed results exist of it serving as a disease marker [36]. Bastick et al. [37] found that TNF- $\alpha$ was predictive for knee OA progression. In this study, there was a statistically significant decrease in TNF- $\alpha$ at two weeks post-therapy in the seaweed pack group. This might be interpreted as a positive prognostic factor for applying seaweed packs on osteoarthritic knees. However, further studies are needed to assess the use of groups of biochemical markers as indices of disease severity or prognostic factors [36].

There are some limitations in this study. Firstly, this study had no control group and could not be performed blindly. Second, we made the seaweed pack using ground fresh seaweed, but we did not have evidence that this was the most effective method. Further study is needed to determine the best method for preparing the seaweed pack. Finally, the study was underpowered to make any conclusion about the difference between groups. This study showed low statistical power $(31 \%)$ when calculating the difference in the WOMAC score immediately post-therapy between the groups, perhaps because of the small number of subjects in the study. This study was designed as a pilot study. Though this study showed that seaweed pack therapy had a positive effect on knee OA, detailed intervention protocols (pack applying time, frequency per day, total intervention times) for effective therapy were not clear. Therefore, further studies addressing these specific components are needed.

\section{Acknowledgements}

This study was a part of the project titled 'The base study to discover and to commercialize for the resources of sea healing to activate marine industry', funded by the Ministry of Oceans and Fisheries, Korea (20170242).

\section{Conflict of Interest}

The authors declared no potential conflicts of interest with respect to the authorship and/or publication of this article.

\section{References}

1. Bijlsma JW, Knahr K. Strategies for the prevention and management of osteoarthritis of the hip and knee. Best Pract Res Clin Rheumatol 2007;21:59-76.

2. Caban-Martinez AJ, Lee DJ, Fleming LE, Tancredi DJ, Arheart KL, LeBlanc WG, et al. Arthritis, occupational class, and the aging US workforce. Am J Public Health 2011;101:1729-34.

3. Brown GA. AAOS clinical practice guideline: treatment of osteoarthritis of the knee: evidence-based guideline, 2nd edition. J Am Acad Orthop Surg 2013;21:577-9.

4. Altman R, Asch E, Bloch D, Bole G, Borenstein D, Brandt K, et al. Development of criteria for the classification and reporting of osteoarthritis: Classification of osteoarthritis of the knee. Arthritis Rheum 1986;29:1039-49.

5. Ray WA, Griffin MR, Stein CM. Cardiovascular toxicity of valdecoxib. N Engl J Med 2004;351:2767.

6. Nussmeier NA, Whelton AA, Brown MT, Langford RM, Hoeft 
A, Parlow JL, et al. Complications of the COX-2 inhibitors parecoxib and valdecoxib after cardiac surgery. N Engl J Med 2005;352:1081-91.

7. Sayed AA, Sadek SA, Solimán AM, Marzouk M. Prospective effect of red algae, Actinotrichia fragilis, against some osteoarthritis aetiology. Afr J Tradit Complement Altern Med 2016; $14: 231-41$.

8. Sherman G, Zeller L, Avriel A, Friger M, Harari M, Sukenik S. Intermittent balneotherapy at the Dead Sea area for patients with knee osteoarthritis. Isr Med Assoc J 2009;11:88-93.

9. Forestier R, Genty C, Waller B, Françon A, Desfour H, Rolland $\mathrm{C}$, et al. Crenobalneotherapy (spa therapy) in patients with knee and generalized osteoarthritis: a post-hoc subgroup analysis of a large multicentre randomized trial. Ann Phys Rehabil Med 2014; 57:213-27.

10. Forestier R, Françon A. Crenobalneotherapy for limb osteoarthritis: systematic literature review and methodological analysis. Joint Bone Spine 2008;75:138-48.

11. Özkuk K, Gürdal H, Karagülle M, Barut Y, Eröksüz R, Karagülle MZ. Balneological outpatient treatment for patients with knee osteoarthritis; an effective non-drug therapy option in daily routine? Int J Biometeorol 2017;61:719-28.

12. Espejo Antúnez L, Caro Puértolas B, Ibáñez Burgos B, Porto Payán JM, Torres Piles ST. Effects of mud therapy on perceived pain and quality of life related to health in patients with knee osteoarthritis. Reumatol Clin 2013;9:156-60.

13. Tefner IK, Gaál R, Koroknai A, Ráthonyi A, Gáti T, Monduk P, et al. The effect of Neydharting mud-pack therapy on knee osteoarthritis: a randomized, controlled, double-blind follow-up pilot study. Rheumatol Int 2013;33:2569-76.

14. Odabasi E, Turan M, Erdem H, Tekbas F. Does mud pack treatment have any chemical effect? A randomized controlled clinical study. J Altern Complement Med 2008;14:559-65.

15. Bellometti S, Galzigna L, Richelmi P, Gregotti C, Bertè F. Both serum receptors of tumor necrosis factor are influenced by mud pack treatment in osteoarthrotic patients. Int $\mathrm{J}$ Tissue React 2002;24:57-64.

16. Evcik D, Kavuncu V, Yeter A, Yigit I. The efficacy of balneotherapy and mud-pack therapy in patients with knee osteoarthritis. Joint Bone Spine 2007;74:60-5.

17. Bostan B, Sen U, Güneş T, Sahin SA, Sen C, Erdem M, et al. Comparison of intra-articular hyaluronic acid injections and mud-pack therapy in the treatment of knee osteoarthritis. Acta Orthop Traumatol Turc 2010;44:42-7.

18. Myers SP, Mulder AM, Baker DG, Robinson SR, Rolfe MI, Brooks L, et al. Effects of fucoidan from Fucus vesiculosus in reducing symptoms of osteoarthritis: a randomized placebo-controlled trial. Biologics 2016;10:81-8.

19. Myers SP, O'Connor J, Fitton JH, Brooks L, Rolfe M, Connellan $\mathrm{P}$, et al. A combined phase I and II open label study on the effects of a seaweed extract nutrient complex on osteoarthritis. Biologics 2010;4:33-44.

20. Frestedt JL, Kuskowski MA, Zenk JL. A natural seaweed derived mineral supplement (Aquamin F) for knee osteoarthritis: a randomised, placebo controlled pilot study. Nutr J 2009;8:7.
21. Frestedt JL, Walsh M, Kuskowski MA, Zenk JL. A natural mineral supplement provides relief from knee osteoarthritis symptoms: a randomized controlled pilot trial. Nutr J 2008;7:9.

22. Shin HC, Hwang HJ, Kang KJ, Lee BH. An antioxidative and antiinflammatory agent for potential treatment of osteoarthritis from Ecklonia cava. Arch Pharm Res 2006;29:165-71.

23. Sukenik S, Flusser D, Abu-Shakra M. The role of spa therapy in various rheumatic diseases. Rheum Dis Clin North Am 1999; 25:883-97.

24. Güngen G, Ardic F, Findıkoğlu G, Rota S. The effect of mud pack therapy on serum YKL-40 and hsCRP levels in patients with knee osteoarthritis. Rheumatol Int 2012;32:1235-44.

25. Ceccarelli F, Perricone C, Alessandri C, Modesti M, Iagnocco A, Croia $\mathrm{C}$, et al. Exploratory data analysis on the effects of non pharmacological treatment for knee osteoarthritis. Clin Exp Rheumatol 2010;28:250-3.

26. Oosterveld FG, Rasker JJ. Treating arthritis with locally applied heat or cold. Semin Arthritis Rheum 1994;24:82-90.

27. Fioravanti A, Cantarini L, Guidelli GM, Galeazzi M. Mechanisms of action of spa therapies in rheumatic diseases: what scientific evidence is there? Rheumatol Int 2011;31:1-8.

28. Melzack R, Wall PD. Pain mechanisms: a new theory. Science 1965;150:971-9.

29. Bellometti S, Poletto M, Gregotti C, Richelmi P, Bertè F. Mud bath therapy influences nitric oxide, myeloperoxidase and glutathione peroxidase serum levels in arthritic patients. Int J Clin Pharmacol Res 2000;20:69-80.

30. Beer AM, Junginger HE, Lukanov J, Sagorchev P. Evaluation of the permeation of peat substances through human skin in vitro. Int J Pharm 2003;253:169-75.

31. Odabaşı E, Turan M, Erdem H, Pay S, Güleç M, Karagülle MZ, et al. The effect of mud pack treatment in knee osteoarthritis: diz osteoartritinde peloidoterapinin etkisi. Turk J Rheumatol 2009; 24:72-6.

32. Claessen KM, Ramautar SR, Pereira AM, Smit JW, Biermasz NR, Kloppenburg M. Relationship between insulin-like growth factor- 1 and radiographic disease in patients with primary osteoarthritis: a systematic review. Osteoarthritis Cartilage 2012;20: 79-86.

33. Kim SB, Park SH, Yoon KS, Lee KW, Kwak H, Park KA. The change of serum and synovial IGF-I level in patients with knee osteoarthritis. Ann Rehabil Med 2005;29:87-91.

34. Schlaak JF, Schwarting A, Knolle P, Meyer zum Büschenfelde $\mathrm{KH}$, Mayet W. Effects of Th1 and Th2 cytokines on cytokine production and ICAM-1 expression on synovial fibroblasts. Ann Rheum Dis 1995;54:560-5.

35. Aggarwal BB, Gupta SC, Sung B. Curcumin: an orally bioavailable blocker of TNF and other pro-inflammatory biomarkers. Br J Pharmacol 2013;169:1672-92.

36. Mabey T, Honsawek S. Cytokines as biochemical markers for knee osteoarthritis. World J Orthop 2015;6:95-105.

37. Bastick AN, Belo JN, Runhaar J, Bierma-Zeinstra SM. What are the prognostic factors for radiographic progression of knee osteoarthritis? A meta-analysis. Clin Orthop Relat Res 2015;473: 2969-89. 